TAO, Vol. 17, No. 2, 331-343, June 2006

\title{
Mechanical Properties, Slip and Nucleation of the 1999 Chia-Yi Earthquake: the Question of Static Stress Influence from the 1999 Chi-Chi Earthquake
}

\author{
Shu-Hao Chang ${ }^{1}$ and Wei-Hau Wang ${ }^{2, *}$ \\ (Manuscript received 13 July 2004, in final form 16 March 2006)
}

\begin{abstract}
We investigate the effects of static stress transfer from the 1999 ChiChi Taiwan earthquake to the subsequent Chia-Yi earthquake by using Coulomb failure assumptions. Our results provide substantive evidence that changes in normal stress unclamped the Chia-Yi rupture surface but that changes in shear stress discouraged the Chia-Yi earthquake. Combining these two counter effects, we determine that the Chia-Yi earthquake could have been activated by the Chi-Chi earthquake provided that there was an increase in Coulomb failure stress of less than 0.2 bars on the grounds that a friction coefficient of $0.7 \leq \mu \leq \mathbf{0 . 7 5}$ and a Skempton's coefficient of $0.75 \leq \beta \leq \mathbf{0 . 8 5}$ are very feasible mechanical conditions. Equally important, we find a poor correlation between the changes in Coulomb failure stress from the Chi-Chi earthquake and the slip amplitudes of the Chia-Yi earthquake, which implies that fault heterogeneity could have very well reduced the effects of the changes in static stress caused by the Chi-Chi earthquake. Beyond this, the concentration of transient stress at the rupture front of the Chia-Yi earthquake was evidently large enough to have overcome the influence of fault heterogeneity and to have dominated slip amplitude there.
\end{abstract}

(Key words: Chia-Yi earthquake, Chi-Chi earthquake, Static stress change)

\section{INTRODUCTION}

A positive correlation between changes in static stress induced by a preshock and the

\footnotetext{
${ }^{1}$ Institute of Seismology, National Chung Cheng University, Taiwan, ROC

2 Institute of Applied Geophysics, National Chung Cheng University, Taiwan, ROC

* Corresponding author address: Prof. Wei-Hau Wang, Institute of Applied Geophysics, National Chung Cheng University, Taiwan, ROC; E-mail: seiwhwg@eq.ccu.edu.tw
} 
distribution of peak seismic slip on the fault surface of a subsequent event has been reported in many studies, among which some of the most notable have been those of the 1954 Fairview Peak-Dixie Valley sequence (Caskey and Wesnousky 1997), the 1989 Loma Preieta-Lake Elsman sequence (Perfettini et al. 1999), the 1992 Landers-Big Bear sequence (King et al. 1994) and the 1992 Landers-1999 Hector Mine earthquakes (Parsons and Dreger 2000). This paper contributes to this line of research since it demonstrates something quite different from this phenomenon; it investigates stress transfer from the September 21, $1999 \mathrm{M}_{\mathrm{w}}=7.6$ Chi-Chi earthquake onto the fault plane of the October 22, $1999 \mathrm{M}_{\mathrm{w}}=5.9$ Chia-Yi earthquake.

The Chia-Yi earthquake was located about $55 \mathrm{~km}$ southwest of the epicenter of the ChiChi earthquake, and this event has been at the center of a flurry of discussions largely because of its proximity to the Meishan fault on which another devastating event had occurred in 1906, killing 1258 inhabitants (Fig. 1). The close spatial relationship between the 1906 Meishan earthquake and the 1999 Chia-Yi earthquake, together with the clustering of the aftershocks of the Chia-Yi earthquake, has led to the claim that both events were a consequence of the episodic dextral motion of the Meishan fault, which itself represents one segment of a dextral contractional strike-slip duplex (Biq 2000). Under the assumption that the Chia-Yi and Meishan earthquakes shared a similar fault mechanism, as claimed above, recent studies have, nevertheless, indicated that the Chi-Chi earthquake would have inhibited the Chia-Yi earthquake by producing a stress shadow at its hypocenter (Wang 2000; Wang and Chen 2001). This notion may actually seem unreasonable in that, as mentioned earlier, the Chi-Chi and Chia-Yi earthquakes were closely related in both time and space and very few earthquakes with a magnitude larger than 5 have been reported near the epicenter of the Chia-Yi earthquake since 1973. These facts alone imply that the chances of the Chia-Yi earthquake occurring spontaneously or stochastically are limited. Recent seismological studies have, in fact, shed light on this by demonstrating that the Chia-Yi rupture was most likely a backthrust rather than a dextral strike-slip fault (Wen and Chen 2003; Chang et al. 2004). For this very finding, we are compelled, first, to reconsider the possibility that the Chi-Chi earthquake might have triggered the Chia-Yi event and, secondly, to explore the mechanical properties of the Chia-Yi rupture that could have enabled this.

Above and beyond these goals, we also test the widely held view that there is a positive correlation between changes in the static stress from the mainshock and the slip amplitudes of the aftershocks. Also, we examine whether the location of the maximum increment in the static stress corresponds to the nucleation site of the Chia-Yi earthquake. Finally, we evaluate the effects of the changes in the temporal static stress after the nucleation of the Chia-Yi event on the slip distribution all along the fault.

\section{FAULT MODELS AND STRESS CALCULATIONS}

To mimic the non-planar Chelungpu fault previously observed in geological surveys (CGS 2000), we employ the 3D slip model of the Chi-Chi earthquake proposed by Wang et al. (2001) who demonstrated this model, which incorporates a 3D fault surface, to be considerably more capable of explaining coseismic surface displacements when compared with a slip 


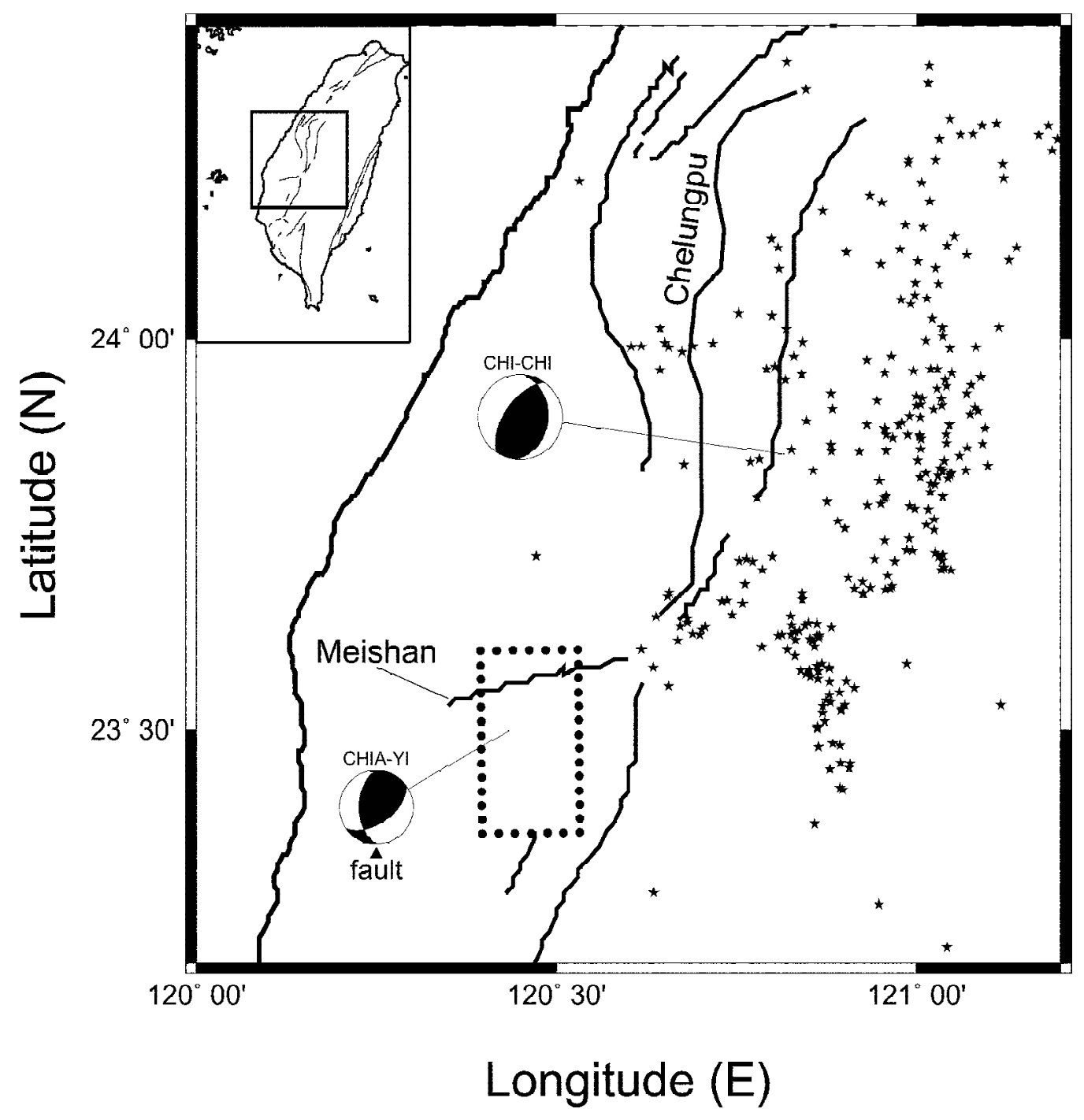

Fig. 1. Focal mechanisms of the Chi-Chi and the Chia-Yi earthquakes, as given by Chang et al. (2000) and Wen and Chen (2003). The black stars denote the epicenters of the aftershocks with a local magnitude greater than 3.0 in the time span between the Chi-Chi and the Chia-Yi events. The rectangular area surrounding the epicenter of the Chi-Yi earthquake is the vertical projection of the Chia-Yi rupture surface shown in Figs. 2, 4 and 6. Note that the Chia-Yi earthquake has been identified as a NS striking blind backthrust with the east tip line buried $5.5 \mathrm{~km}$ deep beneath the earth surface (Wen and Chen 2003). 
model with a planar fault. While the Chi-Chi earthquake is characterized by a large surface rupture, the Chia-Yi earthquake is considered to have been a blind backthrust (Chang et al. 2004 ) with a strike of $179^{\circ}$ and a dip of $51^{\circ}$ to the west (Wen and Chen 2003) as opposed to a foreland vergent thrust, as suggested by Chi and Dreger (2003). Figure 1 shows the vertical projection of the Chia-Yi rupture, which is on a planar fault $28 \mathrm{~km}$ along strike and $26 \mathrm{~km}$ along dip. The fault plane is divided into $14 \times 13$ fault patches with corresponding slip vectors on each fault patch as previously derived by Wen and Chen and shown here in Fig. 2.

We calculate stress transfer by using Coulomb failure assumptions, which state that Coulomb failure stress $(C F S)$ on a specified fault plane is defined as:

$$
C F S=\tau+\mu(\sigma+p)-C,
$$

where $\tau$ is the shear stress on the plane (computed in the slip direction); $\mu$ is the coefficient of friction; $\sigma$ is the normal stress on the plane (positive for tension); $p$ is the pore fluid pressure and $C$ is cohesion. When it is assumed that $\mu$ and $C$ are constant over time, then the values of the changes in the Coulomb failure stress $(\triangle C F S)$ on the specified fault plane can be determined by:

$$
\Delta C F S=\Delta \tau+\mu(\Delta \sigma+\Delta p)
$$

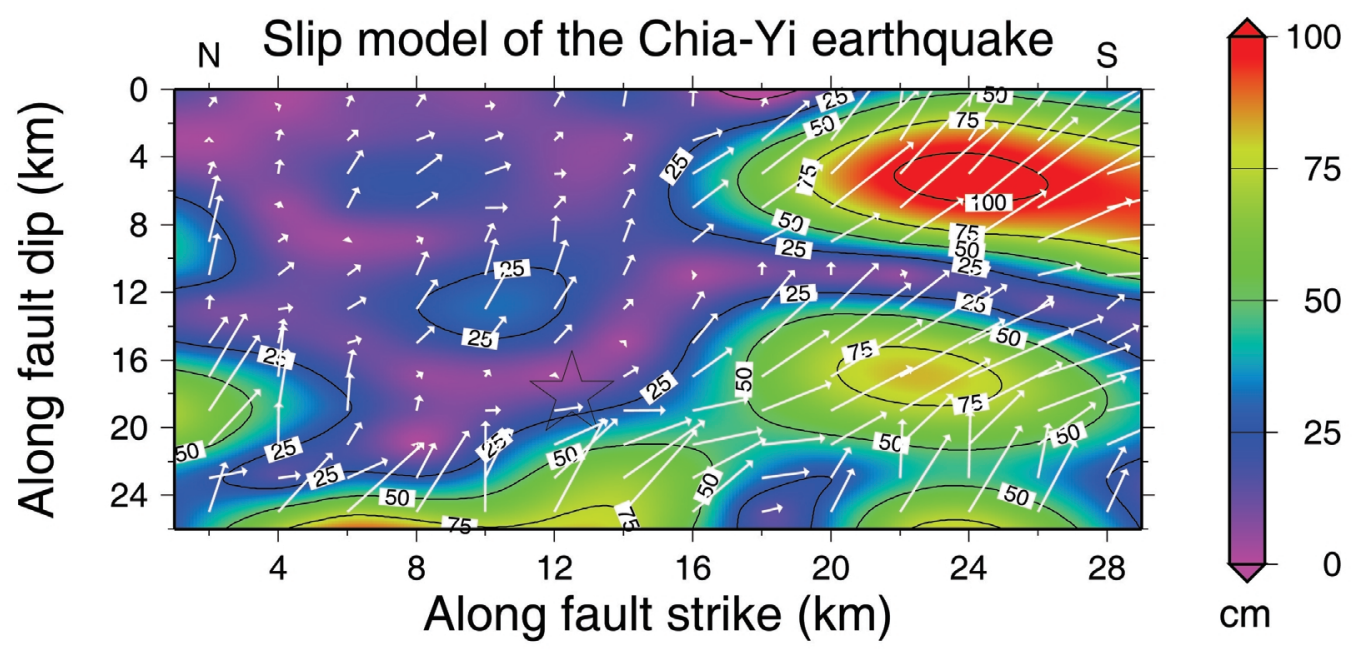

Fig. 2. Slip distribution of the Chia-Yi earthquake, as derived by Wen and Chen (2003). The contour values denote the amplitudes of the slip. Note that large slip amplitudes (asperities) are found to the right of the focus (the star) of the Chia-Yi earthquake. 
According to Rice and Cleary (1976), changes in pore pressure under undrained conditions is given by:

$$
\Delta p=-\beta \frac{\Delta \sigma_{k k}}{3},
$$

where $\beta$ is Skempton's coefficient (Skempton 1954), and $\sigma_{k k}$ is the sum of the diagonal elements of the stress tensor. Theoretically, $\beta$ ranges from 0 (dry) to 1 (fully saturated). Positive $\triangle C F S$ values indicate a shorter time to rupture, or in terms of rate-and-state-dependent friction, an increase in the seismicity rate and vice versa (Dieterich 1994). We use Okada's (1992) dislocation method to calculate the displacements and their derivatives in a homogeneous elastic half-space from a slip on a rectangular fault. It is important to note that in this study, we simulate the Chi-Chi rupture by using multiple rectangular subfaults, as proposed by Wang et al. (2001). We then convert changes in static strain, which are derived from the spatial derivatives of the calculated displacements, to changes in the stress tensors at the centroid of each target fault patch. We do so by employing a modulus of rigidity of $2.68 \times 10^{10} \mathrm{~N} \mathrm{~m}^{-2}$ and a Poisson's ratio of 0.25 . Given Cauchy's law, we are then able to resolve these stress tensors into changes in normal and shear stress that are required for the determination of $\triangle C F S$ on a target fault plane in the slip direction.

\section{STATIC STRESS CHANGES ON THE FAULT PLANE OF THE CHIA-YI EARTH- QUAKE}

We evaluate the changes in the static stress at the hypocenter of the Chia-Yi earthquake to validate whether this event could have been triggered, at least in part, by the Chi-Chi earthquake. Yet, of course, such an analysis requires knowledge of the mechanical parameters of the material in the fault zone, which are usually difficult to obtain. Instead of making an arbitrary guess, we calculate the values of $\triangle C F S$ at the focus using a broad range (from 0 to 1 ) of friction and Skempton's coefficients. What our results indicate is that an increase in the value of $\triangle C F S$ at the hypocenter of the Chia-Yi earthquake would have required that the fault rocks have larger friction coefficients or smaller Skempton's coefficients (Fig. 3). In order to trigger the Chia-Yi earthquake, i.e., for there to have been a positive $\triangle C F S$ at the focus, the friction and Skempton's coefficients of the fault rocks would have had to have fallen in the white area of Fig. 3. In fact, since it has often been reported that most rocks have similar mechanical properties, i.e., $0.6 \leq \mu \leq 0.85$ (Byerlee 1978) and $0.7 \leq \beta \leq 1.0$ (Green and Wang 1986; Berge et al. 1993), which correspond to the small rectangular area in Fig. 3, we can narrow down the feasible mechanical conditions for static stress to have been a trigger to the area where the small rectangular and the white areas intersect.

Note that under these feasible mechanical conditions, which roughly correspond to $0.7 \leq \mu \leq 0.75$ and $0.75 \leq \beta \leq 0.85$, the Coulomb stress at the focus of the Chia-Yi event may have increased by less than 0.2 bars, for say, an average of 0.1 bars. To calculate stress changes 


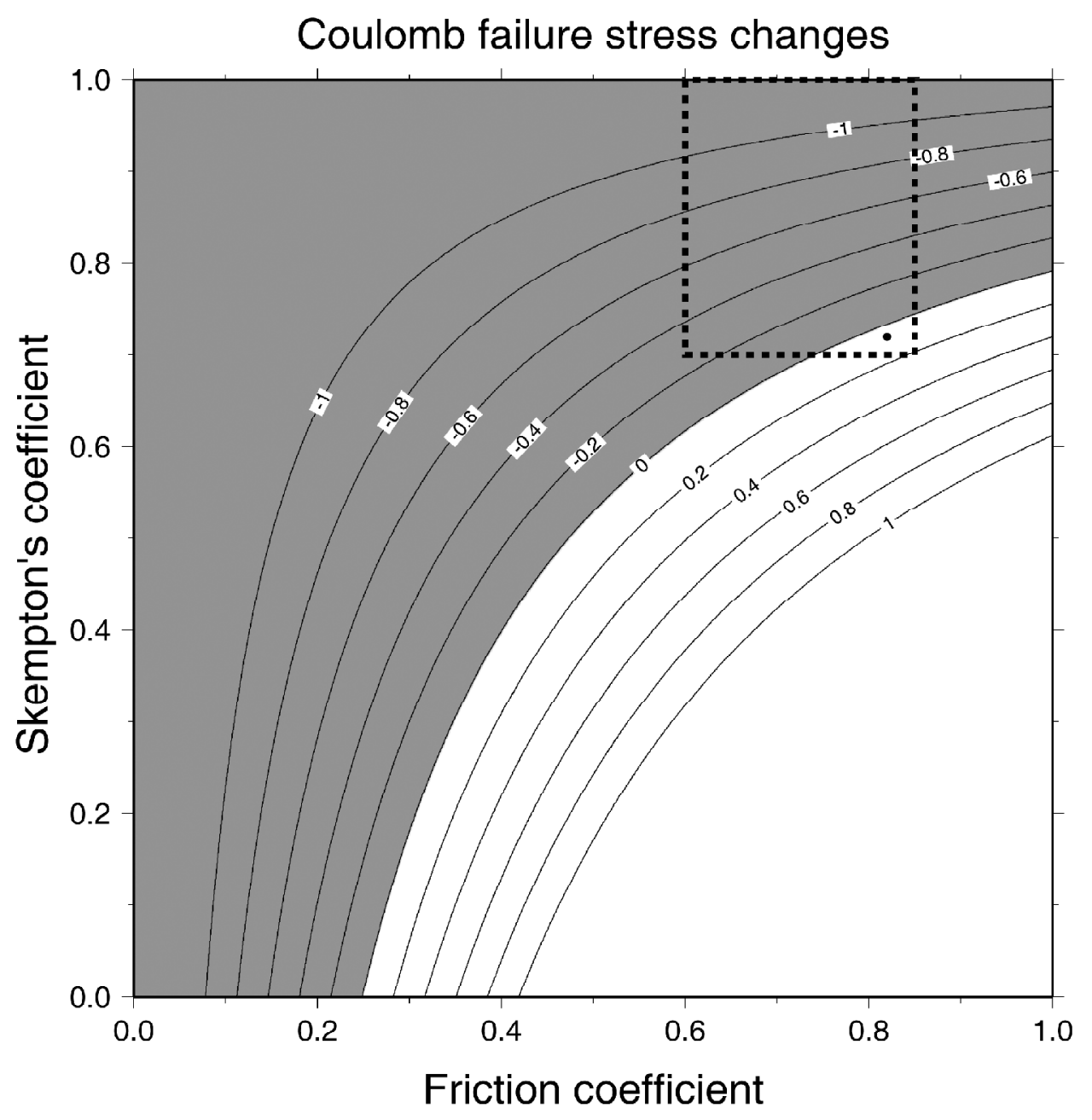

Fig. 3. Changes in the Coulomb failure stress $(\triangle C F S)$ transferred from the ChiChi earthquake onto the hypocenter of the Chia-Yi earthquake with various friction $(\mu)$ and Skempton's coefficients $(\beta)$. The white area indicates the region with positive $\triangle C F S$ values, while the rectangular area confined by the dashed lines defines $\mu$ and $\beta$ for most rocks (Byerlee 1978; Green and Wang, 1986; Berge et al. 1993). The optimal $\mu$ and $\beta$ values at the site of the Chia-Yi event, therefore, fall in the region where the rectangular and the white areas intersect with an average $\triangle C F S$ value of about $0.1 \mathrm{bar}$. The small black dot corresponding to $\mu=0.82$ and $\beta=0.72$ is one example obtained by combining these two mechanical properties to yield a $\triangle C F S$ value of 0.1 bar at the focus of the Chia-Yi earthquake. 
over the entire Chia-Yi rupture plane, for convenience, we assume a friction coefficient of 0.82 and a Skempton's coefficient of 0.72 for the fault rocks, which implies a stress increment of 0.1 bars at the focus, equal to the mean $\triangle C F S$ stated above. This assumption, although not rigorously justified, does not affect the relative distribution of the static stress on the fault surface, which is our main point of interest here.

Figure 4a shows the changes in the normal stress on the Chia-Yi rupture surface caused by the Chi-Chi earthquake. Particularly noteworthy is that the increases in the positive (tensile) normal stress along most of the entire Chia-Yi rupture plane (Fig. 4a) indicate that it was unclamped by the Chi-Chi earthquake. However, these changes in the normal stress, which gradually increase toward the northern edge of the fault plane, have a fairly low correlation with the amplitudes of the slip of the Chia-Yi rupture, which gradually increase toward the southern edge of the fault plane. While the increases in tensile normal stress appear to have provoked the rupturing of the Chia-Yi plane, the decreases in the shear stress induced by the Chi-Chi earthquake seem to have prevented most of the rupture area of the Chia-Yi earthquake from failing (Fig. 4b). Combining these two opposing effects, we find clear evidence that positive $\triangle C F S$ values only occurred in areas to the north of the focus where the fault slip is relatively small. Against this, we find negative $\triangle C F S$ values in areas to the south of the focus where the slip vectors are large (Fig. 4c). Also important, the area with peak Coulomb stress enhancement is about $8 \mathrm{~km}$ away from the focus. These findings suggest that the transfer of static stress from the Chi-Chi earthquake could not have predicted where the Chia-Yi rupture was to nucleate and where the major energy of the Chia-Yi earthquake was to be nucleated.

\section{DISCUSSIONS}

The poor correlation between the $\triangle C F S$ values induced by the Chi-Chi earthquake and the slip amplitudes of the Chia-Yi earthquake are, in plain terms, contradictory to the observations of several of the studies mentioned above (e.g., King et al. 1994; Caskey and Wesnousky 1997; Perfettini et al. 1999; Parsons and Dreger 2000) which have all made the case that positive $\triangle C F S$ values are most commonly associated with areas of large slip. One likely explanation for this inconsistency may very well be that other events in the time period between the Chi-Chi and the Chia-Yi earthquakes could have altered the state of stress on the Chia-Yi rupture surface. To test this, we analyze the transfer of static stress from seven large aftershocks of the Chi-Chi earthquake with a magnitude greater than 5.8, as shown in Fig. 5a. Our results indicate that the stress changes from these events are one order smaller than those from the mainshock (Fig. 5b), thus forcing us to reject the notion that the state of stress was significantly modified.

Having to rule out the notion of modified stress notwithstanding, it is worth bearing in mind that our case is closely in line with the one reported by Utkcuc et al. (2003) who have shown that the $\triangle C F S$ values of the 1999 Izmit earthquake had little effect, if any, on the fault slip distributions of the subsequent 1999 Düzce event. Hence, we attribute the poor correlation between the $\triangle C F S$ values induced by the Chi-Chi earthquake and the slip amplitudes of the Chia-Yi earthquake to fault heterogeneity. In terms of stress-to-failure, such heterogeneity 

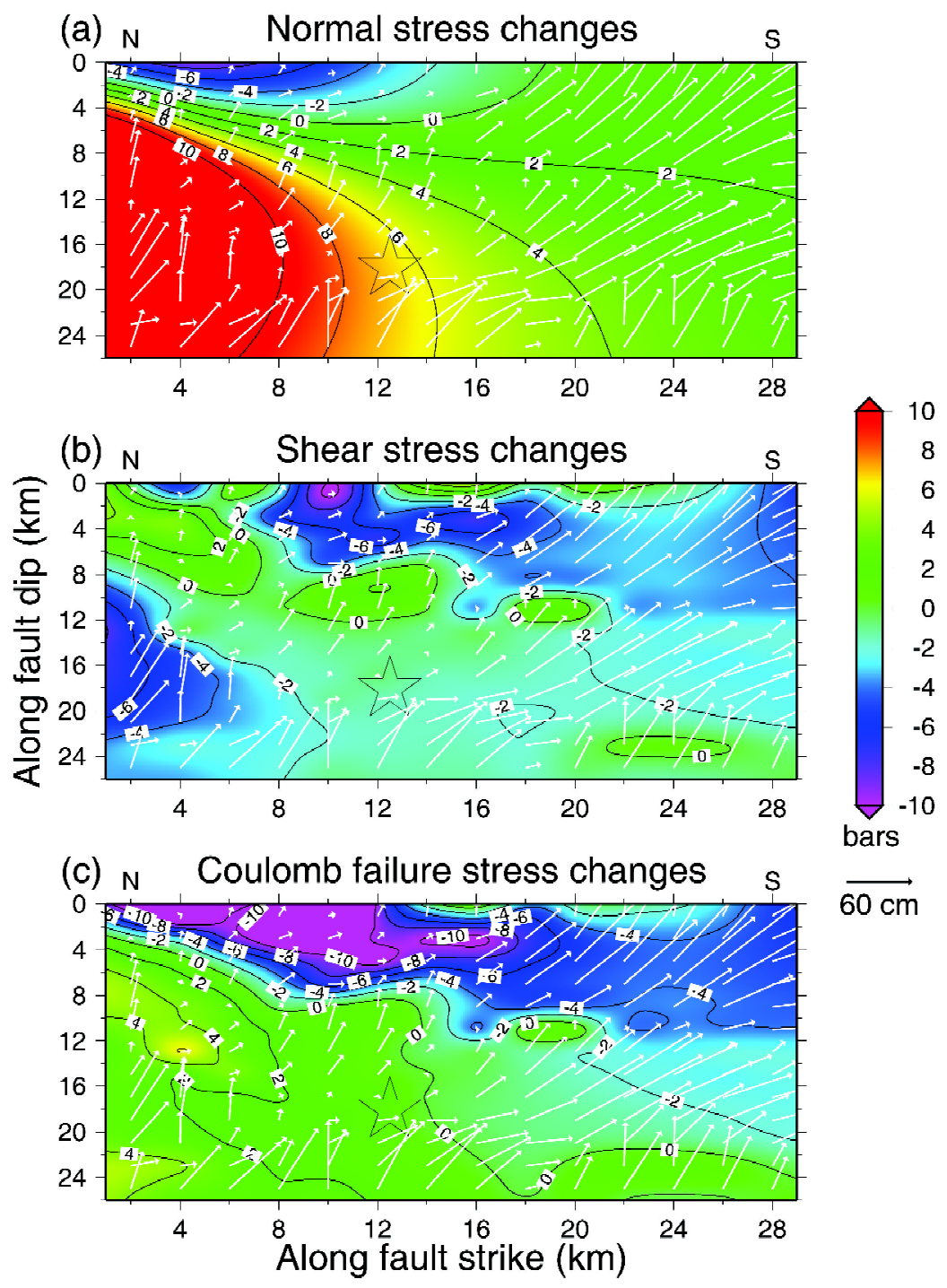

Fig. 4. Changes in static stress in the Chia-Yi rupture surface induced by the Chi-Chi earthquake in terms of (a) normal stress, (b) shear stress and (c) Coulomb failure stress. The star indicates the focus of the Chia-Yi event, while the white arrows are the slip vectors of the Chia-Yi earthquake, as taken from Wen and Chen (2003). 

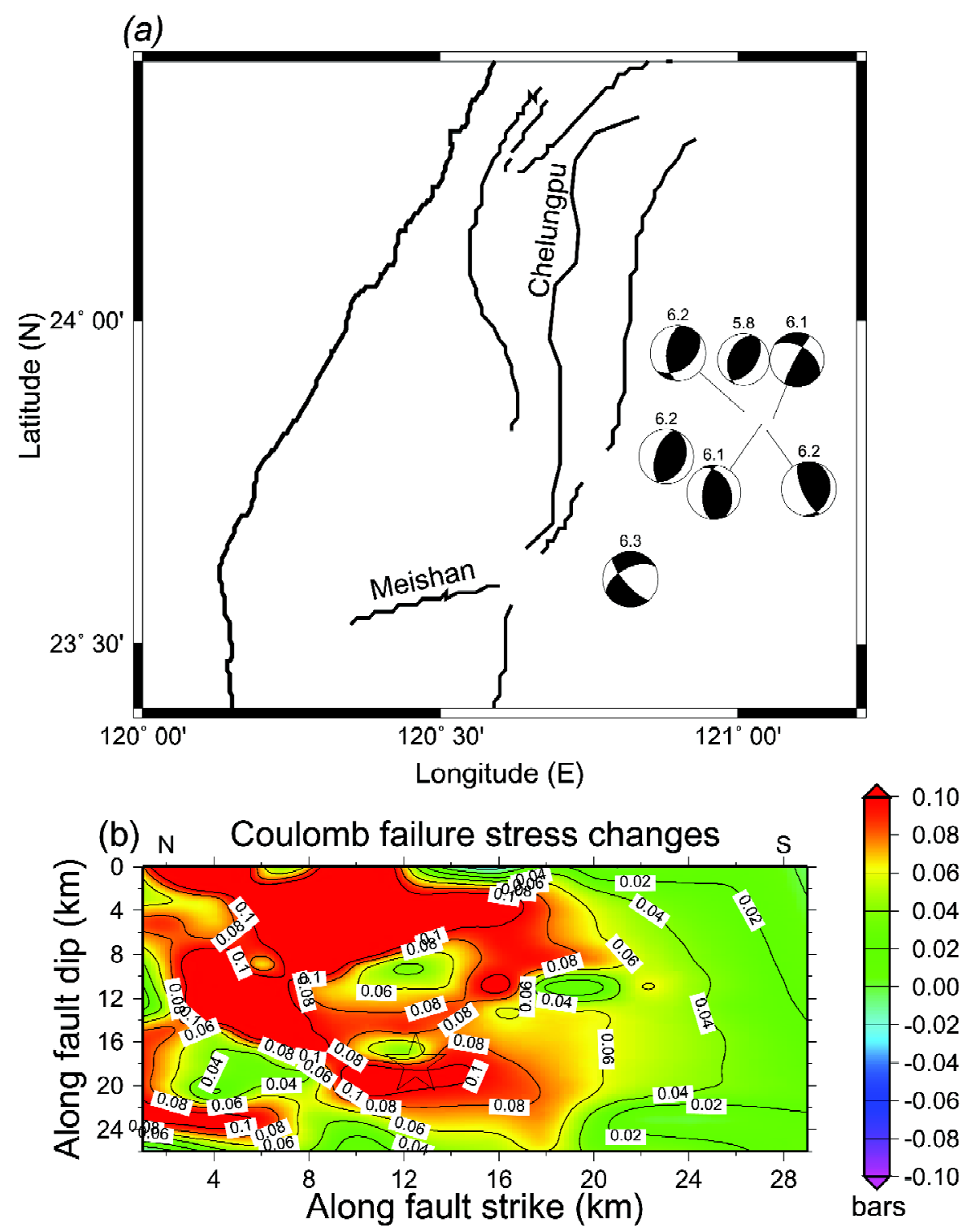

Fig. 5. Stress transfer from seven large aftershocks of the Chi-Chi earthquake onto the Chia-Yi rupture plane. (a) Distribution of the aftershocks. (b) Cumulative changes in Coulomb failure stress from these events. Note that the changes in cumulative stress are about one order less than those from the Chi-Chi mainshock. 
could have resulted from variations in the intrinsic mechanical strength of the fault rocks or from variations in the inhomogeneous pre-stress on the fault surface. Miller et al. (1999) have demonstrated that a fault which has uniform mechanical properties and which is initially subjected to lateral homogeneous stresses can have quite a heterogeneous distribution of stress several thousand years after continuous tectonic loading. It appears that the heterogeneity of the fault limited the effects of the transfer of stress from the Chi-Chi earthquake on the determination of the nucleation site and led to the low correlation with the fault slip of the Chia-Yi earthquake.

It is of particular interest to identify which factors were responsible for the slip pattern of the Chia-Yi rupture. One possible factor is obvious: the changes in stress during the propagation of the Chia-Yi rupture. We evaluate such a possibility by calculating the changes in temporal stress ahead of the Chia-Yi rupture front in three rupture stages with two-second time intervals. We determine the location of the rupture front in each rupture stage by using the value of the rupture velocity of $2.5 \mathrm{~km} \mathrm{~s}^{-1}$, as determined by Wen and Chen (2003). Note that we derive the calculated changes in Coulomb failure stress, as shown in Fig. 6, from the slip behind the rupture front and that we ignore the effect of dynamic stress. It is clear that two seconds after nucleation, the $\triangle C F S$ values are highly elevated near the rupture front, especially in regions where large slips occur (Fig. 6a). Similar results are found when the rupture is further propagated outward (four seconds after initiation, Fig. 6b). At this moment, the $\triangle C F S$ values increase over 10 bars around the major asperities with a slip of up to $80 \mathrm{~cm}$, but only 0 to 2 bars of stress enhancement are observed in regions with a slip of less than $15 \mathrm{~cm}$. Six seconds after initiation, the coupling of $\triangle C F S$ and slip amplitude still persist (Fig. 6c).

As demonstrated above, for the Chia-Yi earthquake, rather than reflect the changes in stress caused by the Chi-Chi earthquake, the areas with large slip are generally associated with large stress enhancement during rupture propagation. This gives a first-order constraint on the fault heterogeneity of the Chia-Yi rupture such that stress-to-failure on the fault plane prior to the Chia-Yi event must have been large enough to reduce the effects of the stress transfer from the Chi-Chi earthquake but must have still been relatively smaller than the stress changes associated with rupture propagation to allow the stress concentration at the rupture front to dominate the fault slip. A better understanding of fault heterogeneity, however, requires a much more thorough investigation and, in particular, a dynamic modeling of the spontaneous rupturing process of the Chia-Yi earthquake.

\section{CONCLUSIONS}

The static stress changes transferred from the Chi-Chi earthquake could have triggered the subsequent Chia-Yi event by increasing the Coulomb stress by less than 0.2 bars at the nuclear site. Judging from the mechanical properties of common rocks, we are firmly of the view that the friction coefficient was most likely in the range of 0.7 to 0.85 and that Skempton's coefficient was between 0.7 and 0.75 . Stress transfer from the Chi-Chi earthquake, however, must have been too small to overcome fault heterogeneity. As a consequence, it could not have contributed to the slip distribution of the Chia-Yi event; nor could it have predicted the nucle- 


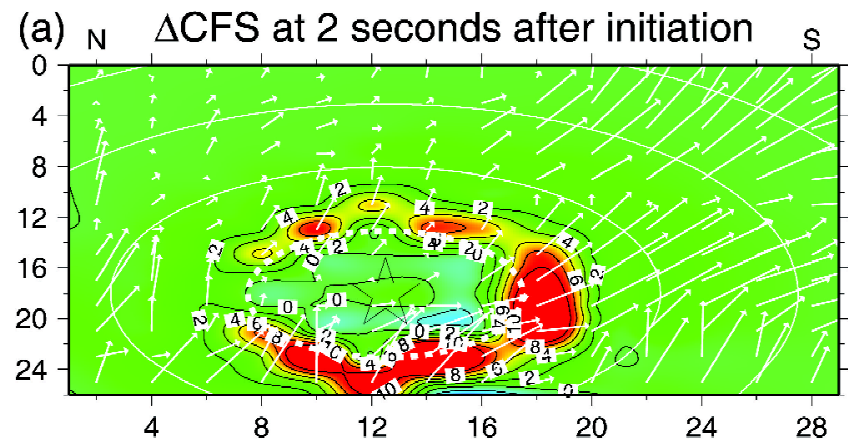

(b) $\mathrm{N} \quad \triangle$ CFS at 4 seconds after initiation $\mathrm{s}$
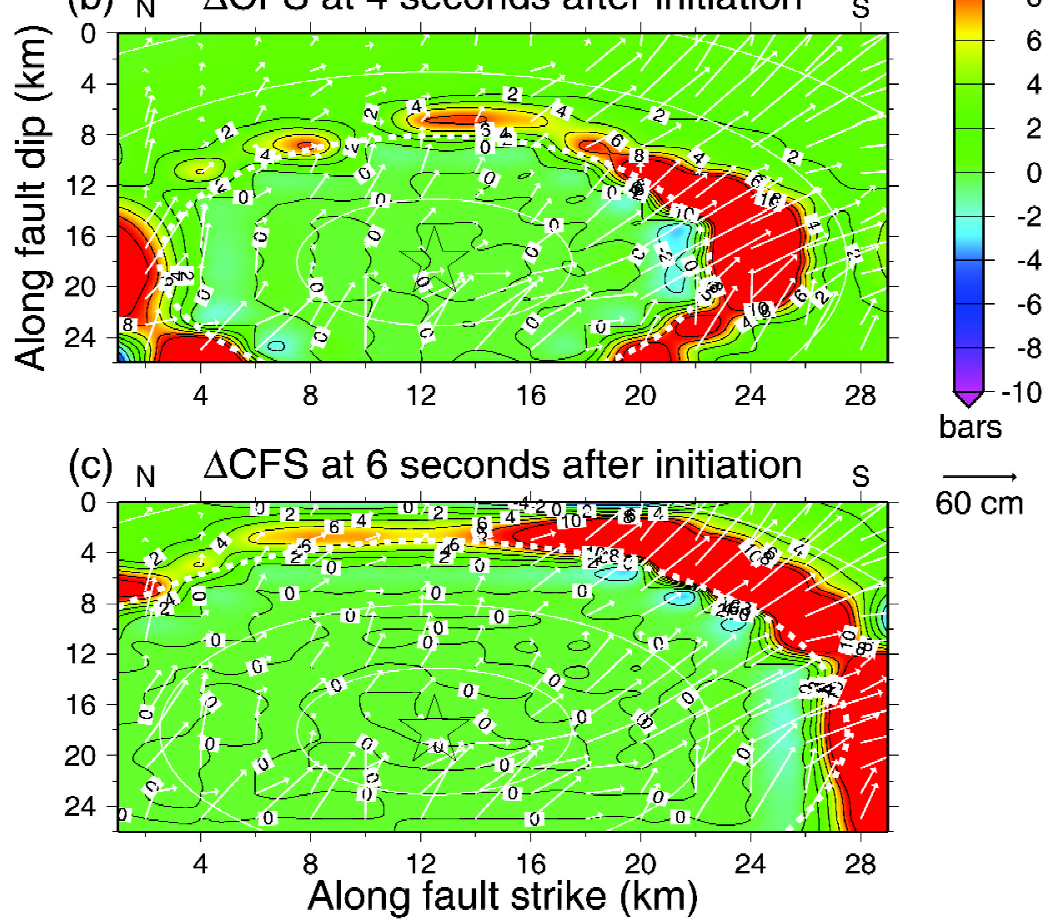

Fig. 6. Temporal variations in the changes in the Coulomb failure stress due to the propagation of the Chia-Yi rupture. Changes in cumulative stress are calculated ahead of the rupture front in different stages during the rupture: (a) at 2 seconds (b) at 4 seconds, and (c) at 6 seconds after the nucleation of the Chia-Yi earthquake. The solid white, circular lines indicate isochrones in each with a 2-second interval, while the dashed white, circular lines denote the rupture fronts. The arrows denote the slip vectors of the Chia-Yi earthquake. Note that the temporal variations in the changes in Coulomb failure stress are fairly consistent with the slip amplitudes which occur just ahead of the rupture front. 
ation site. Instead, most energy must have been released at locations where static stress had been greatly enhanced during the outward rupture propagation of the Chia-Yi mainshock.

Acknowledgments The authors would like to thank Strong Wen and Chau-Huei Chen for providing the rupture images of the 1999 Chia-Yi earthquake. They are also grateful for illuminating discussions with $\mathrm{Wu}-\mathrm{Cheng} \mathrm{Chi}$ and are indebted to Jian-Cheng Lee and Chia-Yu Liu for their perceptive and careful reviews that have helped us to improve the overall quality of this manuscript. This work was supported by the National Science Council, R.O.C., under grant NSC902119M194003.

\section{REFERENCES}

Berge, P. A., H. F., Wang, and B. P. Bonner, 1993: Pore pressure buildup coefficient in synthetic and natural sandstones. Int. J. Rock Mech. Min. Sci. Geomech. Abstr., 30, 1135-1141.

Biq, C., 2000: The 1999 Chia-I earthquake of Taiwan and the coseismic strike-slip duplexing. Spec. Publ. Cent. Geol. Sur., 12, 183-190.

Byerlee, J. D., 1978: Friction of rocks. Pure Appl. Geophys., 116, 615-626.

Caskey, S. J., and S. G. Wesnousky, 1997: Static stress changes and earthquake triggering during the 1954 Fairview Peak and Dixie Valley earthquakes, central Nevada. Bull. Seism. Soc. Am., 87, 521-527.

Chang, C. H., Y. M. Wu, T. C. Shin, and C. Y. Wang, 2000: Relocation of the 1999 Chi-Chi earthquake in Taiwan. Terr. Atmos. Ocean. Sci., 11, 581-590.

Central Geological Survey, 2000: Report on the geological survey of the 1999 Chi-Chi earthquake. Cent. Geol. Surv., Taipei, Taiwan. (in Chinese)

Chang, T. Y., B. Delouis, C. P. Chang, J. Y. Yen, C. H. Chang, K. F. Ma, Y. I. Chen, and Y. B. Tsai, 2004: Seismotectonic study on the Chia-Yi earthquake, Oct. 22 1999. Chinese Geophys. Soc. Sym., Prog. Proc., 81 pp.

Chi, W. C., and D. Dreger, 2004: Crustal deformation in Taiwan: Results from finite source inversions of six $\mathrm{M}_{\mathrm{w}}>5.8$ Chi-Chi aftershocks. J. Geophys. Res., 109, B07305, doi: 10.1029/2003JB002606.

Dieterich, J., 1994: A constitutive law for rate of earthquake production and its application to earthquake clustering. J. Geophys. Res., 99, 2601-2618.

Green, D. H., and H. F. Wang, 1986: Fluid pressure response to undrained compression in saturated sedimentary rock. Geophysics, 51, 948-956.

King, G. C. P., R. S. Stein, and J. Lin, 1994: Static stress changes and the triggering of earthquakes. Bull. Seism. Soc. Am., 84, 935-953.

Miller, S. A., Y. Ben-Zion, and J. P. Burg, 1999: A three-dimensional fluid-controlled earthquake model: Behavior and implications. J. Geophys. Res., 104, 10621-10638.

Okada, Y., 1992: Internal deformation due to shear and tensile faults in a half-space. Bull. Seism. Soc. Am., 82, 1018-1040. 
Parsons, T., and D. S. Dreger, 2000: Static-stress impact of the 1992 Landers earthquake sequence on nucleation and slip at the site of the $1999 \mathrm{M}=7.1$ Hector Mine earthquake, southern California. Geophys. Res. Lett., 27, 1949-1952.

Perfettini, H., R. S. Stein, R. W. Simpson, and M. Cocco, 1999: Stress transfer by the 1988$1989 \mathrm{M}=5.3$ and 5.4 Lake Elsman foreshocks to the Loma Prieta fault: unclamping at the site of peak mainshock slip. J. Geophys. Res., 104, 20169-20182.

Rice, J. R., and M. P. Cleary, 1976: Some basic stress diffusion solutions for fluid-saturated elastic porous media with compressible constituents. Rev. Geophys., 14, 227-241.

Skempton, A. W., 1954: The pore pressure coefficients A and B. Geotech., 4, 143-147.

Utkucu, M., S. S. Nalbant, J. McCloskey, S. Steacy, and Ö. Alptekin, 2003: Slip distribution and stress changes associated with the1999 November 12, Düzce (Turkey) earthquake $\left(\mathrm{M}_{\mathrm{w}}=7.1\right)$. Geophys. J. Int., 153, 229-241.

Wang, W. H., 2000: Static stress transfer and aftershock triggering by the 1999 Chi-Chi earthquake in Taiwan. Terr. Atmos. Ocean. Sci., 11, 631-642.

Wang, W. H., and C. H. Chen, 2001: Static stress transferred by the 1999 Chi-Chi, Taiwan, earthquake: effects on the stability of the surrounding fault systems and aftershock triggering with a 3D fault-slip model. Bull. Seism. Soc. Am., 91, 1041-1052.

Wang, W. H., S. H. Chang, and C. H. Chen, 2001: Fault slip inverted from surface displacements during the 1999 Chi-Chi, Taiwan, earthquake. Bull. Seism. Soc. Am., 91, 11671181.

Wen, S., and C. H. Chen, 2003: Rupture image of the 1999 Chiayi earthquake derived from strong-motion data, at http://www.eq.ccu.edu.tw/ lab408/page3.htm.

Chang, S. H., and Wang, W. H., 2006: Mechanical properties, slip and nucleation of the 1999 Chia-Yi earthquake: The question of static stress influence from the 1999 Chi-Chi earthquake. Terr. Atmos. Ocean. Sci., 17, 331-343. 